\title{
La crisis financiera del virreinato de Nueva España a fines de la colonia
}

\author{
John Jay TePaske* \\ DUKE UNIVERSITY
}

\begin{abstract}
Al momento del grito de Dolores la desintegración económica de la administración colonial era ya un hecho. Aquí se analizan las causas y efectos de esa crisis financiera.
\end{abstract}

$\mathrm{N}$ o es tarea fácil marcar con precisión el comienzo de la era de la independencia hispanoamericana, ese momento histórico cuando afloró el carácter social independentista en México y otras regiones de las Indias

- Deseo expresar mi gratitud a la Tinker Foundation, National Endowment for the Humanities, American Philosophical Society, y Duke University Research Council, quienes proveyeron los recursos que hicieron posible este trabajo. Este es parte de un proyecto más amplio en el que se estudia y analiza la estructura fiscal de Perú y México. El profesor Herbert S. Klein, de Columbia University, es coautor de dicho proyecto. El segmento de esta ponencia correspondiente a Nueva España fue presentado en un congreso en la Universidad de California-Irvine, en febrero de 1987. españolas. ${ }^{1}$ Algunos estudiosos ponen énfasis en la transición que colocó en el trono de España a la dinastía de los Borbones y las reformas imperiales que la siguieron; otros señalan como crucial la difusión del pensamiento ilustrado y los ejemplos de las revoluciones en Norteamérica, Francia y Haití; otros, por su parte, argumentan que se inició en el momento en que las tensiones entre crio-

Una versión aumentada del mismo, la cual incluía a Perú, fue presentada en el XIVI Congreso Internacional de Americanistas en Amsterdam, el primero de julio de 1988.

${ }^{1}$ Debemos aclarar desde el principio que esta es una vista panorámica y amplia de las condiciones fiscales de Nueva España durante el periodo de la independencia. 
llos y peninsulares se tornaron insoportables para los primeros, optando éstos por la independencia; algunos señalan la década de 1790 como el inicio del periodo independentista, al momento en que los lazos comerciales entre España y sus colonias fueron transformados radicalmente. Este trabajo sostiene que la época de la independencia se encuentra enmarcada en el contexto del derrumbe del sistema fiscal imperial de Nueva España. En México la desintegración del estado colonial no fue un fenómeno repentino; fue más bien un proceso gradual y aparentemente inexorable, con inicios a principios de la década de 1780 . Al momento del grito de Dolores, esa desintegración era ya un hecho.

\section{INGRESOS Y EGRESOS EN EL MÉXICO COLONIAL TARDIO}

La base para este estudio sobre Nueva España ${ }^{2}$ la constituyen las cartas cuentas de las diversas cajas reales y los registros financieros de entradas y salidas de las reales haciendas de la ciudad de México y de las demás regiones del virreinato. ${ }^{3}$ Desafortunadamente, y en contraste con lo completo de las series del siglo XVIII,

\footnotetext{
${ }^{2}$ Aunque también está basadoen el análisis de los expedientes de los reales oficiales en el Archivo General de Indias (AGI) Sevilla, México, legajos 2348-2386; y otros documentos en AGI, Indiferente General, Legajos 41,43 y 1707-08.

${ }^{3}$ Las cartas cuentas de las diversas cajas de México han sido publicadas en John J. TePaske y Herbert S. Klein, Ingresos y egresos, vols. Iy II, 1986, 1988. El primer volumen incluye las cajas de Acapulco, Arizpe, Bolaños, Campeche, Chihuahua, Durango, Guadalajara, Guanajuato y Mérida; el segundo cubre México, Michoacán, Oaxaca, Pachuca, presidio del Carmen, Puebla de los Ángeles, Rosario, Saltillo, San Luis Potosí, Sombrerete, Tabasco, Veracruz, Zacatecas, y Zimapán.
}

muchas de las cuentas de principios del XIX no se encuentran en los archivos. Esta ausencia se debe a que dichos documentos nunca llegaron a manos del Tribunal de Cuentas de la ciudad de México o a la Real Contaduría de Madrid, debido a las interrupciones en la comunicación entre la colonia y su metrópoli, y al estallido de la lucha independentista en 1810. Las cuentas de la caja central de México sólo llegaron hasta 1817, mientras que las de las regiones mineras de Guanajuato y Sombrerete sólo cubren hasta 1816, exhibiendo, además, lagunas en su contenido. En el caso de Durango sólo han sobrevivido las cartas cuentas anteriores a 1813; en otras cajas reales regionales, como las de Veracruz, Acapulco, Guadalajara, y San Luis Potosí, hay sólo algunas cartas cuentas salteadas, y en algunos casos no hay ninguna disponible. Como nota positiva, puede destacarse que la mayoría de las cartas cuentas del periodo separatista para el rico distrito minero de Zacatecas han sobrevivido; hay también registros de acuñación, series de estados de deudas anuales de las reales haciendas de Nueva España y estadísticas publicadas sobre comercio y recibos aduanales. Estudiadas junto a las cartas cuentas, estas fuentes producen un cuadro bastante completo de las vicisitudes financieras que afectaron al virreinato de Nueva España, durante el agitado periodo de la emancipación. ${ }^{4}$

Durantelasúltimas décadas del periodo colonial los ingresos fiscales alcanzaron su cenit. En la caja real matriz de la ciudad de México, para dar un ejemplo, las entradas aumentaron de un promedio de 2000000 de pesos anuales en la

${ }^{4}$ Las fuentes específicas de este análisis pueden encontrarse al final de este trabajo donde se describen las "Fuentes para las gráficas". 
primera década del siglo XVII hasta más de 14000000 anuales un siglo después; esto es, aumentaron siete veces (véase gráfica 1). Si se consideran los impuestos depositados en la real hacienda central provenientes de las cajas entre $1801 \mathrm{y}$ 1810 (gráfica 2), los ingresos anuales del virreinato alcanzaron un promedio de 20000000 de pesos en esa década, ascendiendo a 28000000 en 1809 , un año antes del levantamiento de Hidalgo. Este aumento resulta impresionante aun cuando se considera el factor inflacionario. ${ }^{5}$

Por lo general, las cajas regionales del virreinato siguieron los mismos patrones de la caja central de la ciudad de México.

\footnotetext{
${ }^{5}$ TePaske, "Economic cycles in New Spain", en R.L. Garner y W.B. Taylor, Iberian colonies, 1985, pp. 119-142; Coatsworth, "The limits of colonial absolutism: the State in eighteenth-century México", en K. Spalding (comp.), Essays 1982, pp. 25-52.
}

En el distrito de Guadalajara, por ejemplo, los ingresos promediaron 163000 pesos al año en la primera década del siglo XVIII y casi 740000 en los primeros diez años del XIX, es decir, cuatro veces más. ${ }^{6}$ En la misma década (1801-10) las recaudaciones de Guanajuato, Zacatecas y Sombrerete alcanzaron sus niveles más altos, al menos nominalmente, y exhibieron, en general, las mismas tendencias alcistas de la capital y Guadalajara. Con contadas excepciones cíclicas o anuales, la tendencia a lo largo del siglo $\mathrm{XIX}$, tanto en la caja central de la ciudad de México como en las cajas regionales, fue de un crecimiento marcado de los ingresos. Éstos llegaron a su más alto

${ }^{6} \mathrm{El}$ ingreso anual promedio de Guadalajara está basado en el quinquenio 1801-1805; no hay datos completos para 1806-1810.

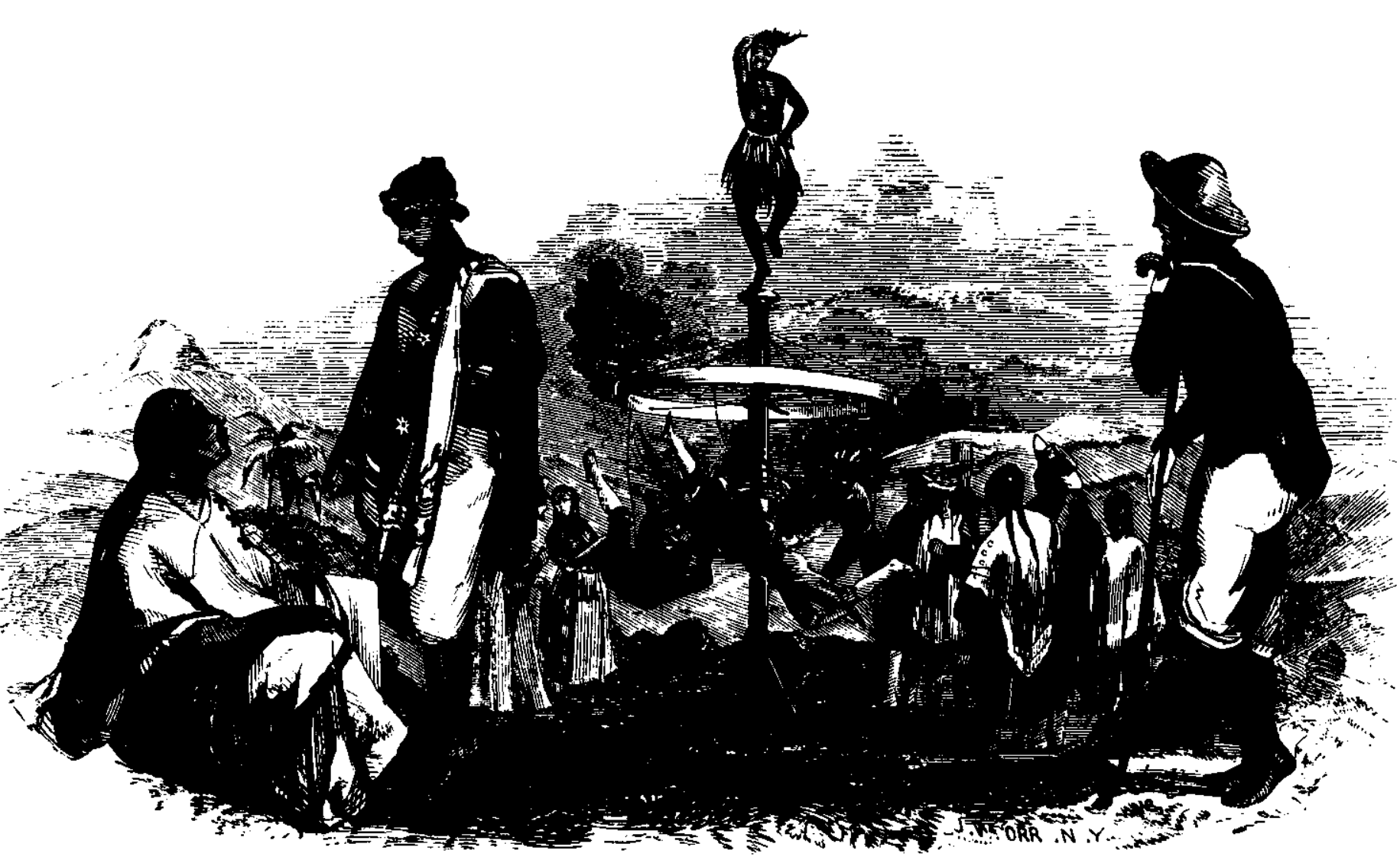


nivel justo en vísperas del levantamiento de Hidalgo. Entre los factores que explican dicha tendencia se encuentran un aumento de cuatro veces en la producción de plata, acompañado de mayores recaudaciones de impuestos argentíferos; la implantación de un sistema más racional y eficiente de cobro de impuestos; nuevas imposiciones fiscales puestas en vigor por los Borbones y sus ministros, especialmente en el último cuarto del XVIII, y el crecimiento poblacional de Nueva España.

Sin embargo, este cuadro color de rosa de aumentos en el renglón de ingresos resulta menos positivo si se atiende al renglón de gastos. Comenzando en las décadas de 1770 y 1780 , cuando la inflación empezaba a reducir los ingresos fiscales, aumentaron dramáticamente los gastos militares. Estos gastosincluían fondos destinados a los situados y a desembolsos extraordinarios ${ }^{7}$ para el sostenimiento de los presidios de la región del Caribe, el armamento de flotas para escoltar los convoyes cargados de plata, y el mantenimiento naval y militar de las Filipinas. Además, en la década de 1770 las remisiones a Castilla aumentaron astronómicamente, de un promedio anual de menos de 1000000 de pesos en décadas previas, hasta casi 5000000 de pesos anuales en la ultima década del XVIII. ${ }^{8}$ Para agravar más la situación, algunos de los nuevos impuestos dirigidos al sostenimiento de programás de índole social y económico, tales como construcción de carreteras, establecimiento de hospitales y servicios legales para la

\footnotetext{
${ }^{7}$ En la primera década del xvill había cerca de 30 renglones de entrada en los libros de la ciudad de México; a finales de siglo había más de cien.

${ }^{8}$ TePaske, "La política en el Caribe", en Antonio Acosta y Juan Marchena (comps.), La influencia de España, 1983, pp. 76-82.
}

población indígena, y pensiones de retiro para funcionarios y militares, no resultaron suficientes, haciendo necesaria la transferencia de otros fondos fiscales. Almismo tiempo, nuevas contribuciones como las reales cotizaciones hechas en los obispados mexicanos para la Real Orden de Carlos III sangraron fuera de Nueva España los fondos necesarios para cubrir las necesidades locales.

Así fue como los déficit empezaron a crecer. A principios de la década de 1770 las deudas de la real hacienda mexicana ascendían a poco más de 3000000 de pesos; para el año 1810, habían aumentado diez veces, llegando a 31000000 de pesos (gráfica 7), sin contarse los atrasos delos situados adeudados a los presidios de la Florida, Cuba, Puerto Rico, Santo Domingo y las Filipinas. ${ }^{9}$ Los funcionarios reales emplearon diversos métodos para contrarrestar estos déficit. Ya hemos señalado que uno de estos consistía en dejar de remitir los situados destinados a la región circuncaribeña y las Filipinas, dejando así los presidios a merced de sus propios recursos. Otra medida era obligar a las diversas instituciones religiosas y privadas a comprar bonos estatales garantizados por el estanco del tabaco o la aduana de la ciudad de México, con un interés de 4 o 5\%. También se obligaba periódicamente a instituciones como el consulado o el Tribunal de Minería a que hicieran préstamos al gobierno con o sin interés. Dicho esto en cifras, las deudas acumuladas por fondos tomados de los capitales de instituciones laicas y religiosas ascendían, en 1810, a 18500000

\footnotetext{
${ }^{9}$ Los virreyes generalmente incluian el monto de los situados atrasados al escribirle a los monarcas sobre las vicisitudes financieras del virreinato. Este renglón no se incluía en las relaciones de deudas remitidas anualmente a España por los oficiales de la Real Hacienda.
} 
pesos; la deuda correspondiente a préstamos alcanzaba, por su parte, la suma de 8500000 pesos. ${ }^{10}$ También se dependía de los donativos al gobierno, recurso éste que ayudó al sostenimiento del Estado desde los primeros años de la colonia.

Hasta 1810 los oficiales reales también cubrieron gastos recurriendo a las reservas de los ramos ajenos o de los particulares $^{11}$ de las cajas donde se habían acumulado enormes capitales que fueron transferidos a la real hacienda. Más susceptibles a esto, fueron en México los ramos de bulas de santa cruzada y novenos. De hecho, para 1798 la real hacienda había secado estas reservas, habiendo tomado 16000000 de pesos de ellas. Esta deuda fueborrada, al menos en los libros, cuando España declaró que las bulas y novenos eran ramos de la real hacienda. Este "alivio" resultó bastante fugaz, ya que la deuda empezó a acumularse nuevamente después de 1805 (véase gráfica 7). Los depósitos, bonos y garantías colocados por funcionarios $\mathrm{e}$ instituciones en las cajas, también fueron apropiados por oficiales de hacienda. Estos fondos, al igual que las temporalidades confiscadas a los jesuitas, se habían extinguido ya para 1810. De hecho, cuando el levantamiento de Hidalgo, no quedaban reservas de los ramos especiales; todos los sobrantes se habían gastado en esfuerzos bélicos y de defensa, tanto en las Indias como en la península. Las instituciones religiosas y laicas, al

${ }^{10} \mathrm{AGI}$, México, legajo 2023. Estado que manifiesta los débitos en que quedó la Tesorería General de Ejército y Real Hacienda de esta capital en 31 de diciembre de $1810 \ldots$... México, 29 de enero de 1811.

${ }^{11}$ Estos ingresos se reservaban específicamente para la corona, obras pías, defensa, construcción de caminos y fines similares. Se los diferenciaba de los ramos de real hacienda. igual que los propietarios mexicanos habían sido exprimidos de tal manera que poco les quedaba para contribuir a las exigencias del empobrecido estado colonial.

\section{INGRESOS Y EGRESOS DE LA HACIENDA} MEXICANA, $1810-1821$

El estallido de las guerras de independencia fue otro fuerte golpe para el debilitado aparato fiscal de Nueva España. Tal como señalábamos anteriormente, en 1809, incluyéndose los ingresos enviados a la ciudad de México por las cajas regionales, entraron a la hacienda central más de 28000000 de pesos (véase gráfica 9), la más alta cifra hasta entonces. Un año después, sin embargo, las entradas se habían reducido 10000000 , a apenas 18000000 de pesos. En 1811 volvieron a bajar hasta 3.5 millones. Desde entonces no sobrepasaron la marca de los $10 \mathrm{mi}$ llones, al menos hasta 1817 . El nadir fue 1812, con 8.7 millones. Dicho esto de otra forma, los ingresos se redujeron $36 \%$ de 1809 a 1810 , otro $21 \%$ entre 1810 y 1811 , y todavía un $36 \%$ de 1811 a 1812 . Considerándose el periodo entre 1809 y 1817 (último año para el que se conservan cuentas de la caja central) la caída fue de $70 \%$. Es más, en 1817 las entradas nominales eran inferiores a las que se recaudaban a fines de la década de 1770.

La principal causa de este descalabro fue la interrupción repentina de los envíos de las diversas cajas regionales a la ciudad de México. Antes de 1810 las cajas de provincias habían sido consistentes en sus envíos de fondos a la capital para servir las necesidades del virreinato y del imperio. Entre 1795 y 1810, estas remisiones a la ciudad de México ascendieron a más de 98400000 pesos (véase gráfica 2), un promedio de 5.8 millones

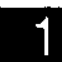


de pesos al año, representando un tercio de todas las recaudaciones registradas en las cuentas de la ciudad de México. Entre 1811 y 1817 , los fondos de las cajas subordinadas enviados a la capital, sólollegaron a 1900000 pesos, para un promedio de 318000 al año. En términos porcentuales, las recaudaciones de las cajas regionales llegaron a constituir sólo $4 \%$ del total recibido, testimonio dramático de la pérdida de ingresos provinciales.

La magnitud de esta crisis puede verse también al analizarse las cifras de las cajas regionales de Zacatecas, Durango y Guanajuato. Entre 1791 y 1810, por ejemplo, los oficiales reales de Zacatecas enviaron cerca de $85 \%$ de sus recaudaciones; entre 1811 y 1821 enviaron menos de $25 \%$. En Guanajuato, aproximadamente $80 \%$ de todos los impuestos cobrados fueron remitidos a la ciudad de México entre 1791 y 1807, envíos que promediaron 1500000 pesos anuales. Entre 1812 y 1816, estas transferencias bajaron a tan sólo $28 \%$ del ingreso fiscal total; más significativo toda vía, las recaudaciones anuales en Guanajuato se redujeron a un promedio de 800000 pesos anuales, la mitad de lo que eran antes del grito de Dolores. Las remisiones de la caja de Durango a la ciudad de México en el periodo 1791-1810, ascendieron a aproximadamente $75 \%$ de los ingresos, con un promedio anual de 375000 pesos; desde 1811 a 1813 estos envíos bajaron a sólo $31 \%$ del total recibido por dicha caja.

Las súbitas bajas en los envíos de las cajas regionales a la ciudad de México no siempre significaron situaciones críticas en los distritos provinciales. A pesar de que las recaudaciones se redujeron en la mayoría de las cajas entre 1810 y 1812 , una vez que pasó el efecto inicial de la guerra, particularmente luego de la de- rrota de Jose María Morelos y el final de la guerra peninsular, los ingresos volvieron a subir, aunque no a los niveles anteriores. En Zacatecas, por ejemplo, a pesar de que la tendencia general fue de disminución, hubo recuperación entre los años 1813-14 y 1816-17 (gráfica 4). Por otro lado, no obstante la carestía de mercurio, la producción minera de $\mathrm{Za}$ catecas se recuperó notablemente, aunque nunca llegó a los niveles anteriores a la independencia (gráfica 5). Las recaudaciones de impuestos sobre ventas también se mantuvieron altas, probablemente debido a aumentos en las tarifas de la alcabala.

El impacto del descenso en las remisiones de las cajas provinciales a la ciudad de México no debe subestimarse. Fuera cual fuese la razón, los oficiales reales de Zacatecas decidieron retener los impuestos localmente antes de verlos partir en caravanas de mulas por caminos peligrosos. Muchos de estos fondos ahora iban a parar a la misma localidad como salarios de militares, gastos que aumentaron enormemente durante las luchas de emancipación. Por ejemplo, en Zacatecas los gastos militares ocupaban anualmente menos de $1 \%$ de los ingresos antes de 1810; a partir de ese año y hasta 1817, ocuparon casi 30\%. En Guadalajara, donde los gastos militares llegaban a 37\% de lo recaudado en los primeros años del XIX, el porcentaje se duplicó, llegando a $73 \%$ en 1816 . El distrito de Guanajuato, donde se gastaba alrededor de $2 \%$ del ingreso en defensa antes de 1810, sellegó a gastar 43\%. También aumentaron otros gastos locales. En Zacatecas se tuvo que incurrir en el gasto de improvisar una casa de acuñación para pesos fuertes. Resulta claro, a pesar de estos gastos, que la guerra de Independencia fue el pretexto que usaron los oficiales locales de hacienda para dejar 


\section{SECUENCIA}

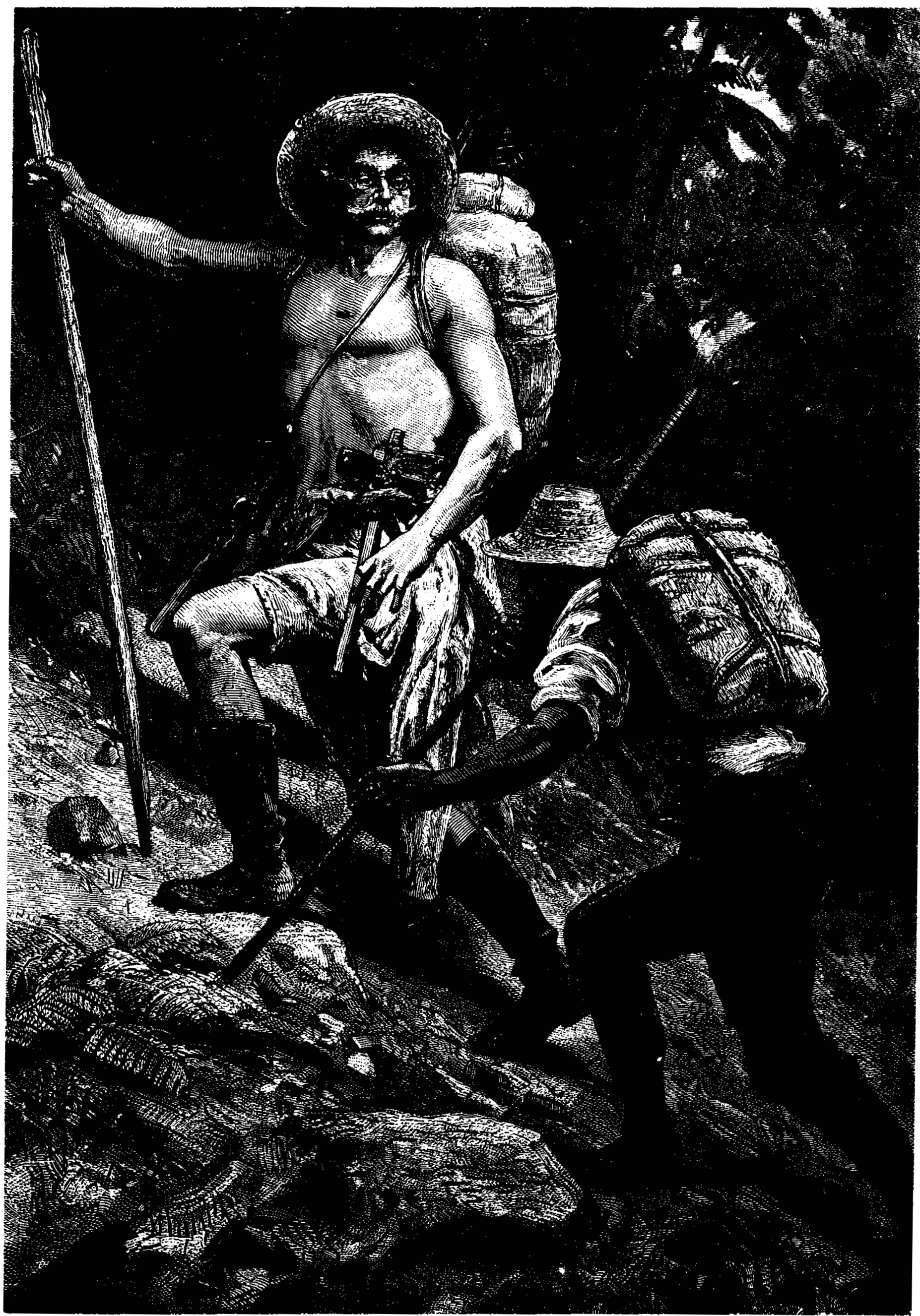


de sostener económicamente el aparato imperial. Estos oficiales entendieron que era mejor usar los recursos para mantener la seguridad y autonomía local antes que enviarlos a las insaciables autoridades del virreinato con sede en la capital. De buenas a primeras se había deshecho la madeja fiscal que había unido en simbiosis a las diversas cajas del virreinato.

La reducción en la producción de plata -y la consecuente disminución de entradas por concepto de esta producciónera otra fuente de problemas para el aparato fiscal mexicano. El análisis de los registros de acuñación indica que la producción minera declinó en general durante la segunda década del siglo XIX (gráfica 6). Entre 1791 y 1810, la Casa de Moneda acuñó un promedio de 23000000 de pesos al año. Para el periodo 1811-21 el promedio descendió en casi dos terceras partes hasta $8500000 \mathrm{al}$ año. (El más crítico de los años fue 1812 cuando sólo se acuñaron 4400000 pesos, cifra que contrasta con el récord de 27100000 en 1805.) Después de 1812 la acuñación creció modestamente hasta 1817, cuando bajó un poco; luego creció hasta alcanzar 12000000 de pesos en 1819. Ya para 1821 la acuñación se había reducido hasta llegar a 5900000 pesos, testimonio vivo del efecto del Ejército de las Tres Garantías en Nueva España. ${ }^{12}$

RESPUESTAS MEXICANAS A LA CRISIS DEL CONFLICTOINDEPENDENTISTA

Considerado el aspecto financiero, la sublevación de Hidalgo no pudo haber

\footnotetext{
${ }^{12}$ Las cifras de acuñación son un excelente indicador de la producción minera. Entre 1691 y 1810 la correlación entre acuñación y producción fue de .98828 y entre 1731 y 1810 fue de .98138 .
}

ocurrido en peor momento. Durante los 30 años previos, las cajas mexicanas habían sido limpiadas de sus excedentes y reservas. Llamadas a prestar y donar una y otra vez, las instituciones clericales y laicas ya no tenían con qué seguir sosteniendo el reino; por su parte, los atrasos de los situados a los presidios caribeños crecían geométricamente. El cuadro era tal que los expertos en finanzas, tanto en España como en México, llegaron al convencimiento de que todo lo que podía ser gravado lo había sido ya, con la excepción de la riqueza indígena, la cual estaba exenta.

En 1810, dada la seriedad del levantamiento popular, el virrey y la hacienda enfrentaron la apremiante necesidad de pagar sueldos a las milicias, tropas regulares y otros gastos de armamento. A pesar de las dificultades, los oficiales de hacienda recurrieron a viejas y nuevas tácticas para contrarrestar las bajas en los envíos regionales. ${ }^{13}$ Entre los viejos métodos se encontraron las loterías forzadas y el aumento de las tarifas de alcabalas y almojarifazgos. La alcabala había subido de 3 a $5 \%$ en la época previa a la independencia hasta $8 \%$ en 1816 . El virrey también gravó con nuevosimpuestos a artículos como el pulque y el tabaco, requirió más préstamos y donativos, y redujo los salarios delos empleados estatales. En 1812 el virrey.Francisco Xavier Venegas aumentó los impuestos a casi todos los productos de consumo urbano (propios y arbitrios) para enfrentar las exigencias de la guerra. Quizás el único método que no utilizáron los oficiales reales fue la transferencia de fondos de

\footnotetext{
${ }^{13} \mathrm{El}$ grueso del peso de los nuevos impuestos recayó sobre la población urbana. Para una descripción excelente de esto véase Timothy E. Anna, The fall..., 1978, pp. 140-161.
} 
un ramo a otro, y esto debido a que en los ramos ajenos y en los particulares ya no quedaba nada que transferir. Los mismos habían sido vaciados en la desesperación por solucionar crisis anteriores. $\mathrm{Al}$ mismotiempola oficialidad gubernamental siguió ignorando sus responsabilidades: pagar a los militares y administradores, enviar los situados de la región circuncaribeña, pagar pensiones, sostener las instituciones piadosas y educativas, y remitir sobrantes a España. Nada de esto, sin embargo, era nuevo. Desde la década de 1780 los mexicanos se habían acostumbrado a los propios y arbitrios, impuestos especiales de tiempos de guerra, y al aumento de las tarifas en los impuestos establecidos. También estaban familiarizados con las peticiones de préstamos voluntarios o involuntarios, donativos forzados, y rebajas en los salarios de los funcionarios. Lo que ahora sucedía era que ya se habían extinguido los fondos de los ramos particulares y ajenos.

En este contexto de desesperación fiscal, los oficiales de hacienda demostraron gran inventiva. En la ciudad de México se las ingeniaron para crear un impuesto de bienes raíces; tanto los propietarios como los arrendatarios, adelantándose al siglo XX, establecieron impuestos escalonados sobre las rentas. En sus primeros cuatro años (hasta marzo de 1816) el nuevo tributo sobre la propiedad inmueble urbana produjo 277000 pesos netos, un promedio de 70000 pesos al año. ${ }^{14}$ Establecido por decreto del virrey a mediados de diciembre de 1813, el impuesto escalonado sobre la renta se fijó en 3\% para salarios de 300 pesos y $12.5 \%$ para salarios de 12000 pesos o

\footnotetext{
${ }^{14}$ AGI, México, legajo 1489. Informe del virrey, México, 4 de marzo de 1816.
}

más. Aún no está claro cuánto produjo este nuevo tributo.

De una u otra manera, los agentes aduaneros se las ingeniaron para mantener los ingresos de la aduana de la ciudad de México bastante estables (gráfica 8). Aunque las recaudaciones de alcabalas bajaron -a pesar de aumentos en sus tarifas- las entradas por otros impuestos como el del aguardiente aumentaron, particularmente después de 1815. Las autoridades también levantaron un nuevo impuesto a los convoyes para cubrir los gastos de mantener abierta la ruta de Veracruz a la capital, lográndose así mantener un mínimo de flujo de bienes. ${ }^{15}$ Resulta interesante que los ingresos aduaneros de la ciudad de México eran 600000 pesos más altos en 1820 que en 1810 . Esto refleja la capacidad de la aduana de poder mantener susingresos mediante nuevos impuestos y nuevas tarifas. Mientras se reducían los envíos de las cajas regionales, la aduana trataba de compensar aumentando sus aportaciones. Esto, sin embargo, no fue suficiente para enfrentar los crecientes gastos militares.

Los fondos hacían falta desesperadamente. En 1795, por ejemplo, el monto total de los gastos militares de la caja central de México ascendieron a 600000 pesos, incluyendo el dinero para el sostenimiento de las milicias y tropas regulares (gráficas 3 y 10). Para 1810 estos gastos se habían triplicado hasta 1600000 , y para 1812 se habían quintuplicado, llegando a 3000000 de pesos. Después de 1812, sin embargo, ya sea por falta de fondos o porque se habían debilitado los rebeldes, comenzaron a

\footnotetext{
${ }^{15} \mathrm{AGl}$, México, legajo 1494. Carta del virrey Juan Ruiz de Apodaca al ministro de Real Hacienda, México, 11 de noviembre de 1817.
} 


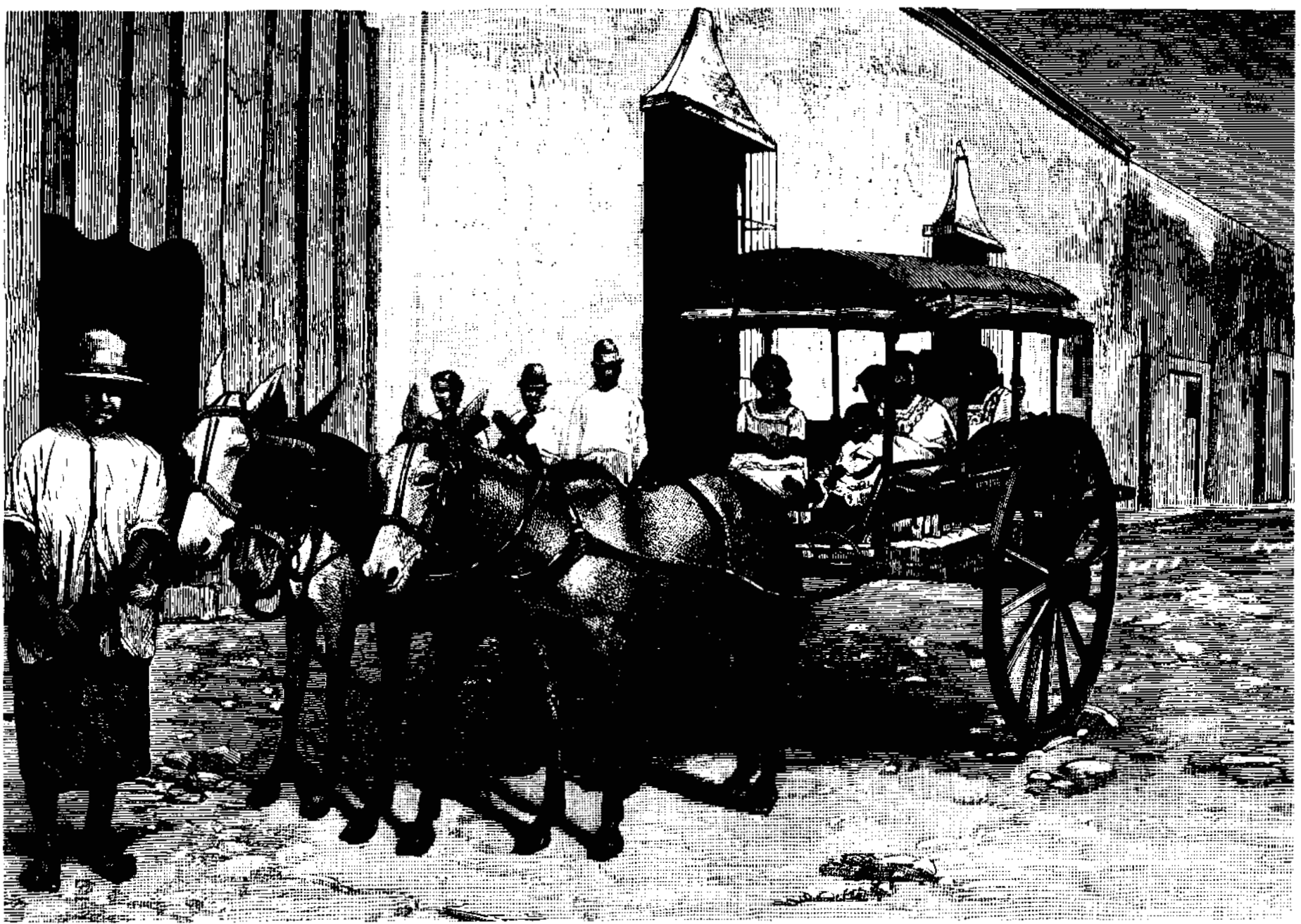

bajar los gastos en este renglón; en 1817 llegaban a poco más de 900000 pesos. La falta de recursos parece ser la causa principal; en una palabra el gobierno virreinal no tenía fondos que gastar. El hecho de que los gobiernos locales tuvieran que hacer esfuerzos desesperados para cubrir sus gastos militares es testimonio del fracaso financiero del gobierno central; hasta entonces los asuntos de defensa habían sido responsabilidad del gobierno virreinal. ${ }^{16}$

Fuera de Nueva España el impacto sobre los presidios caribeños fue más severo aún. Las interrupciones de la

${ }^{16}$ La incapacidad del gobierno virreinal de proveer tropas y equipo bélico fue lo que motivó a los gobiernos locales a buscar recursos para defenderse de los insurrectos. Véase en particular la ponencia de Christon Archer, "La causa buena", en Jaime E. Rodríguez (comp.), The independence of México, 1989, pp. 88-108. guerra afectaron profundamente a Florida, Cuba, Puerto Rico y al presidio del Carmen, además a las Filipinas (gráfica 11). Para el periodo 1795-1810, por ejemplo, los situados enviados por México promediaron 1700000 anuales. Entre 1811 y 1817 los mismos se redujeron a un promedio de solo 80000 pesos, y entre 1815 y 1817 eran prácticamente nulos. Esto deja ver que los presidios del Caribe y las Filipinas fueron los más afectados por las guerras de independencia. Debe notarse la capacidad de supervivencia de estas regiones que hasta entonces habían dependido del situado.

A lo largo de dos décadas, entre 1791 y 1810 , las exigencias bélicas en Europa y América dejaron a las reales haciendas de México en un estado de miseria, que no permitía enfrentar los levantamientos independentistas. En la década de 1790 la deuda había aumentado de 13900000 en 1791 a más de 34000000 en 1798 . Ese 


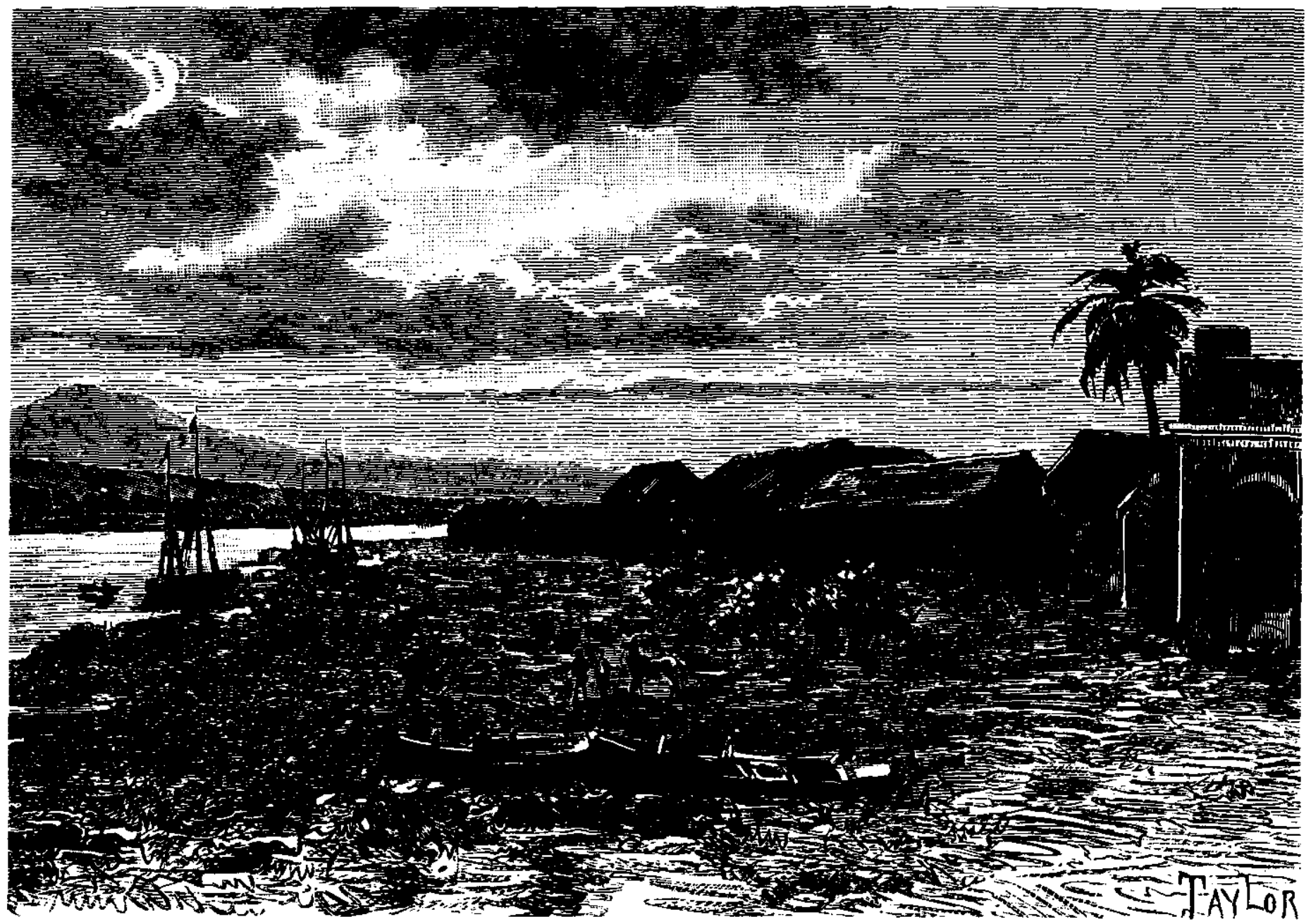

año se redujo la deuda a 22700000 a raíz de la transferencia de los ramos de indulgencias y novenos a la real hacienda (gráfica 7). Los siguientes siete años fueron buenos para la real hacienda de Nueva España, reduciéndose significativamente la deuda a 17400000 pesos. El descalabro se dio en el siguiente quinquenio (1806-10), cuando los ingresos no crecieron al ritmo de los gastos, duplicándose la deuda hasta llegar a 31100000 pesos a fines de 1810 .

Curiosamente, aunque la deuda siguió aumentando después de 1810 -llegó a 37500000 en 1815-la tasa de crecimiento se redujo por razones obvias: los oficiales de la real hacienda no podían seguir exprimiendo económicamente al país, al cual poco le quedaba por ver gravado o secuestrado. Hasta la platería de las iglesias y casas particulares había ido a parar al subsidio del esfuerzo bélico. Por otro lado muchos de la clase acaudalada habían llevado sus capitales fuera del país. Con inflación alta, carestía de artículos de lujo y altos impuestos encareciendo el precio de los productos, el consulado se vio imposibilitado de hacer nuevos préstamos; la producción de plata había declinado, y los ramos especiales dela real hacienda se habían agotado. Un estimado dela época señalaba que en 1816 la deuda de la hacienda mexicana era de 81000000 de pesos, contando 24000000 en situados atrasados. El analista que llegó a dicho estimado creyó que de esa suma podían dejarse de pagar 41000000 , lo que se le debía a la Casa de Moneda, al estanco del tabaco, a los ramos particulares y ajenos, y los situados, entre otros. También podrian borrarse otros 7700000 a no ser que los acreedores pudieran demostrar la legitimidad de la deuda contraída con el consulado, con el juzgado de intestados, con las reales audiencias de México y 
Guadalajara, con las comunidadesindígenas de México, Valladolid y Oaxaca, con los cabildos eclesiásticos de Nuevo León, Valladolid y Guadalajara, con el tribunal de minería y con la real lotería. Los restantes 32000000 tenían que pagarse para mantener el crédito del gobierno y para asegurar la supervivencia de aquellas instituciones religiosas que tanto habían hecho durante los últimos 30 años a favor del esfuerzo bélico en el país y en Europa. ${ }^{17} \mathrm{El}$ pago de la deuda se inició en 1817 cuando diversos acreedores recibieron 2000000 de pesos. Un poco más fue pagado en los siguientes tres años, pero en 1821 el triunfo del ejército de las Tres Garantías hizo de la deuda algo irrelevante.

\section{RECAPITULACIÓN}

El colapso del sistema fiscal mexicano de la época de la independencia se dio por etapas. La primera empezó en la década de 1780 cuando se le impuso nuevas cargas a la real hacienda para sufragar las guerras en ambos lados del Atlántico. En México el resultado de esto fue tener que acudir, hasta extinguirlos, a los fondos de bulas de santa cruzada, temporalidades, novenos, depósitos y otros. Las necesidades también obligaron a tomar prestado a diversas instituciones laicas y religiosas a intereses de 3,4, o 5\%, garantizándolos con el estanco del tabaco y los recibos de aduana. En Nueva España, durante la primera década del siglo $\mathrm{XIX}$, el virreinato también se apropió y vendió tierras pertenecientes a corpora-

${ }^{17}$ Sala de Manuscritos, Biblioteca Nacional, Madrid, doc. 19710, f. 23. Sobre la deuda de la R. Hacienda y medio de restablecer su crédito. Año 1817. ciones piadosas, en un esfuerzo por cubrir los gastos locales y peninsulares. ${ }^{18}$ Es un hecho que para 1810 la oficialidad de la hacienda había recurrido a lo que entendian ser todas las fuentes financieras del virreinato.

El levantamiento de Hidalgo resultó ser sólo otro rudo golpe a la hacienda virreinal, golpe que aumentó la carga del ya sobrecargado sistema fiscal colonial. Ante esta nueva obligación, en un contexto en el cual las arcas de la hacienda se encontraban casi vacías, el gobierno empezó a ignorar algunas de sus responsabilidades, tales como remitir situados al Caribe y otras fronteras del imperio español. En la segunda década del siglo XIX los más afectados por la crisis resultaron ser estos presidios. Más significativa todavía fue la interrupción en las remisiones de sobrantes de las ricas provincias mineras a la caja central de México. Hasta entonces ésta había sido una fuente vital para el sostenimiento del virreinato y de España. Medidas temporales como, por ejemplo, mayores niveles de impuestos, impuestossobre la renta, gravámenes a la propiedad inmueble, préstamos forzados y loterías, transferencias de fondos de un ramo de hacienda a otro, donativos y reducciones salariales para burócratas y militares ayudaron en parte a proveer los recursos para preservar la unidad de México pero no fueron suficientes para controlar el crecimiento de la deuda de la real hacienda.

Para el futuro de México -el estadonación que se gestó durante la época de la independencia-, el hecho más significativo resultó ser el descalabro fiscal del sistema financiero que unía a la ciudad

\footnotetext{
${ }^{18}$ Brian R. Hamnett, "The appropiations", 1969, pp. 85-113.
} 
de México con el resto del país, sistema que por más de tres siglos había enlazado al centro y a la periferia. La reconstrucción de estos vínculos resultaría ser otra tormentosa historia dentro de la forja del Estado mexicano, historia casi tan tormentosa como la de su destrucción.

\section{BIBLIOGRAFIA}

-Alamán, Lucas, Historia de Méjico desde losprimeros movimientos que prepararon su independencia en el año de 1808 hasta la época presente, Libros del Bachiller Sansón Carrasco, México, 5 vols., 1985-1986.

-Anna, Timothy E., The fall of the royal govermment in Mexico city, University of Nebraska Press, Lincoln, 1978.

-Archer, Christon, "La causa buena: the counterinsurgency army and the war of Ten Years", en Jaime E. Rodriguez (comp.), The independence of Mexico and the creation of the new nation, University of California, Los Ángeles, 1989, pp. 88-108.

-Coatsworth, John, "The limits of colonial absolutism: the state in eighteenth-century Mexico", en K. Spaldine (comp.), Essays in the political, economic and social bistory of colonial Latin America, University of Delaware, Newark, 1982.

-Hannett, Brian R., "The appropiations of mexican church wealth by the spanish Bourbon government, Joumal of Latin American Studies, vol. I, 1969.

-Howe, Walter, The mining guild of New Spain and its tribunal general, 1770 1821, Harvard University Press, Cambridge, 1949.

-Ortiz de Ayala, Tadeo, Resumen de la estadística del imperio mexicano, Imprenta de doña Herculana del Villar y Socios, México, 1822.

-TePaske, John Jay, "Economic cycles in New Spain in the eighteenth century: the view from the public sector", en R.L. Garner and W.B. Taylor, Iberian colonies, new world societies: essays in memory of Charles Gibson, edición particular, Pensilvania, 1985.

- _La política española en el Caribe durante los siglos XVII y XVIII", en Antonio Acosta y Juan Marchena (comps.), La influencia de España en el Caribe, la Florida y la Luisiana, 1500-1800, Instituto de Cooperación Iberoamericana, Madrid, 1983.

-TePaske, John Jay y Herbert S. Klein, Ingresos yegresos de la Real Hacienda de Nueva España, vols. I y I, Instituto Nacional de Antropología e Historia, México, 1986, 1988.

Gráfica 1

INGRESOS NETOS DE CAJA MATRIZ DE MÉXICO, 1795-1817

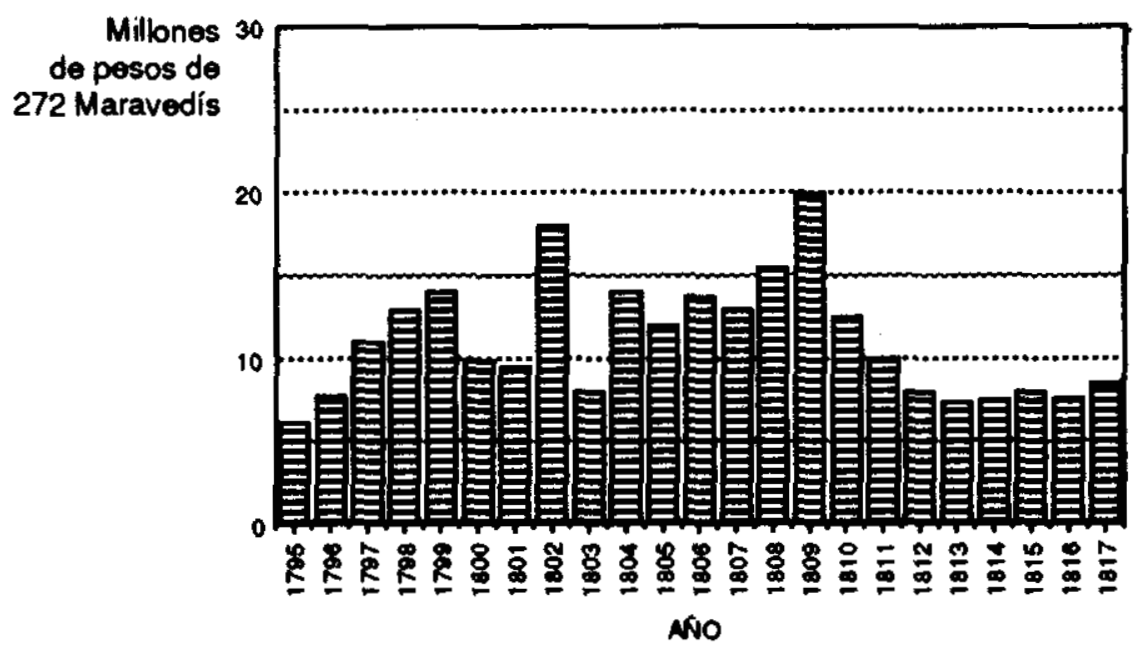

Fuente: Tomadas de las cartas cuentas de AGI, México, legajos 2029 y 2061-72 y de Archivo General de la Nación, México, Libros de Hacienda, 68 y 81. Las cartas cuentas de 1817 provienen del mismo archivo y me fueron proporcionadas atentamente por mi amigo y colega el doctor Juan Carlos Garavaglia. 


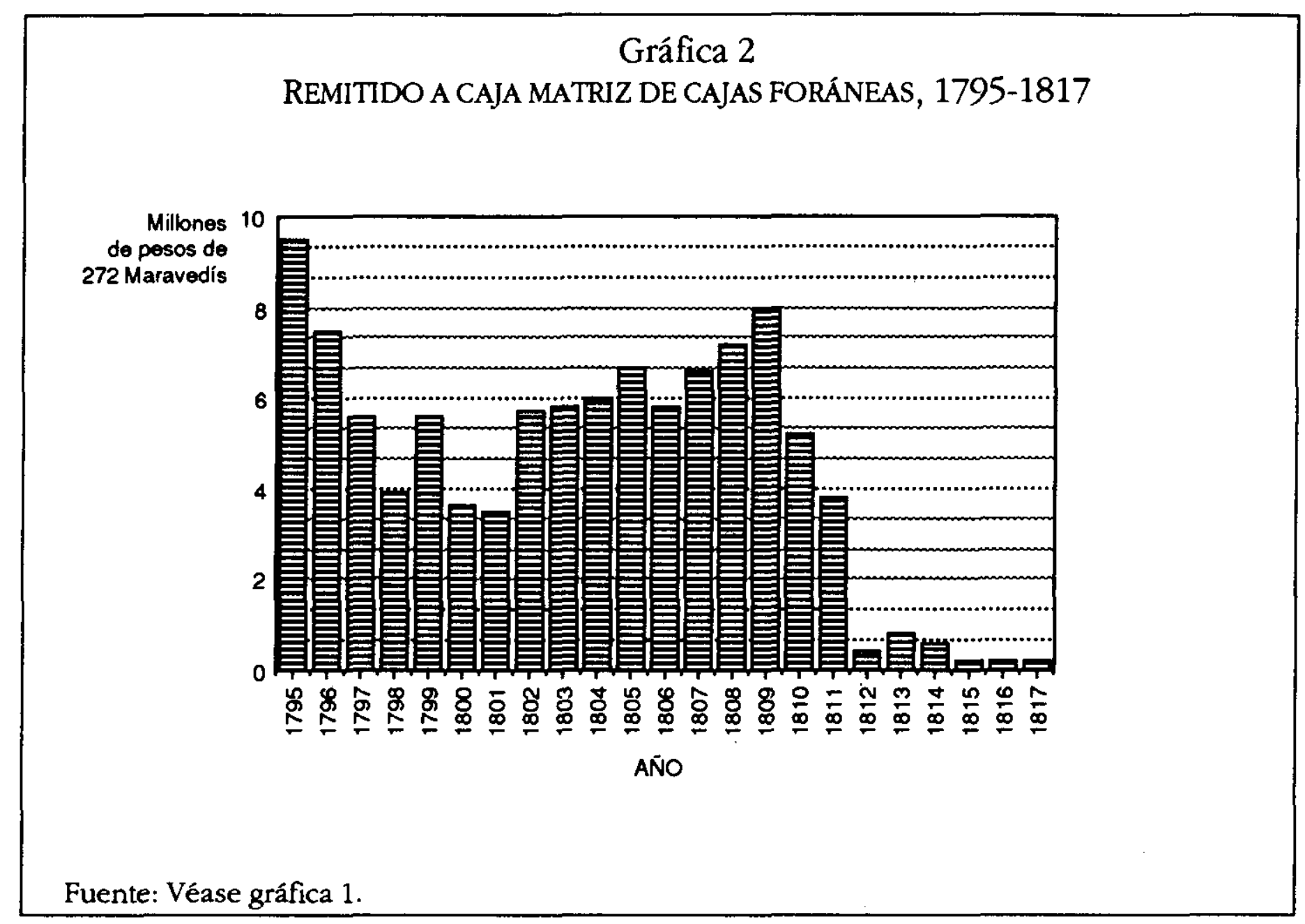

\section{Gráfica 3}

GASTOS DE GUERRA, CAJA MATRIZ DE MÉXICO, 1795-1817

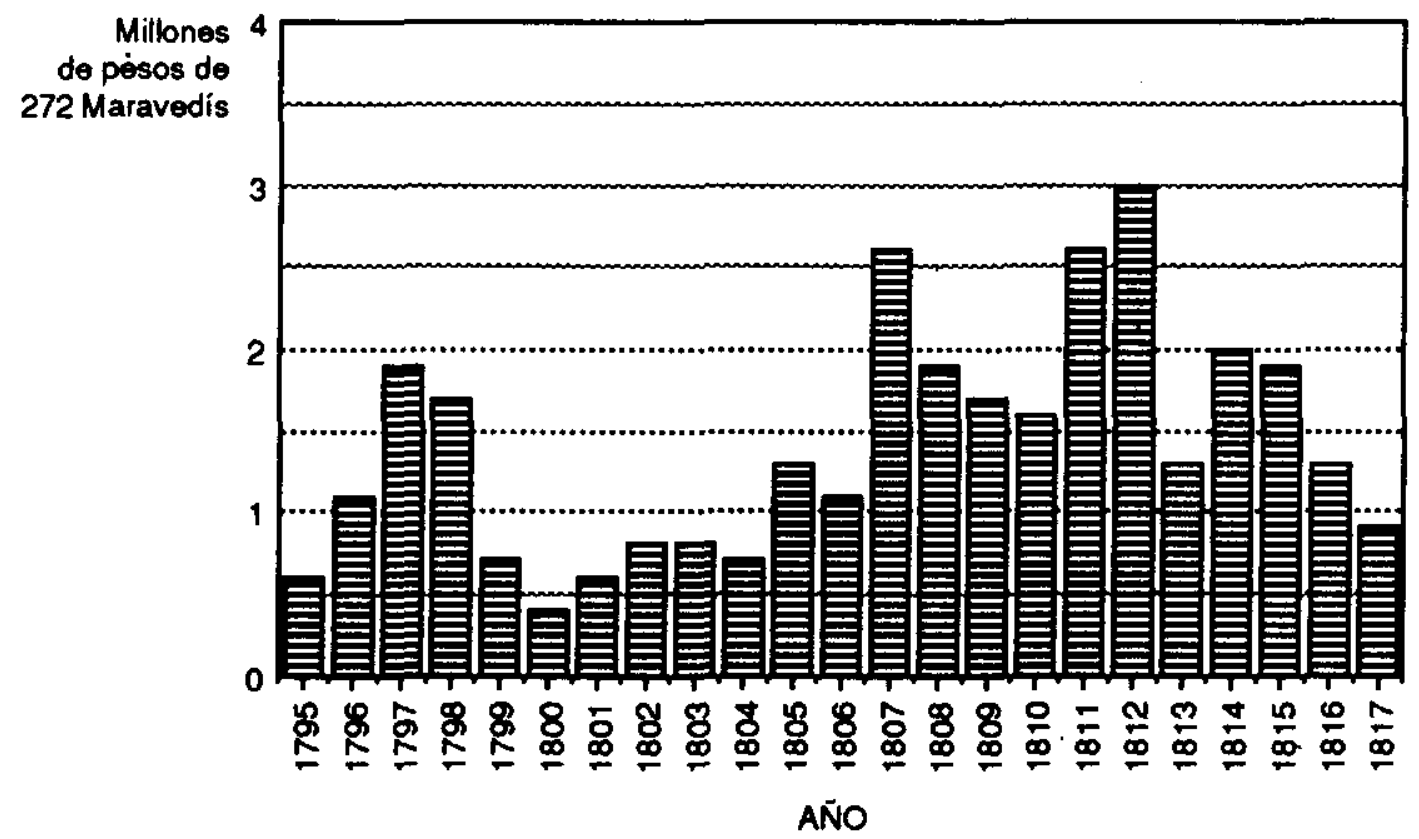

Fuente: Véase gráfica 1. 


\section{Gráfica 4}

INGRESOS, REAL CAJA DE ZACATECAS, 1791-1821

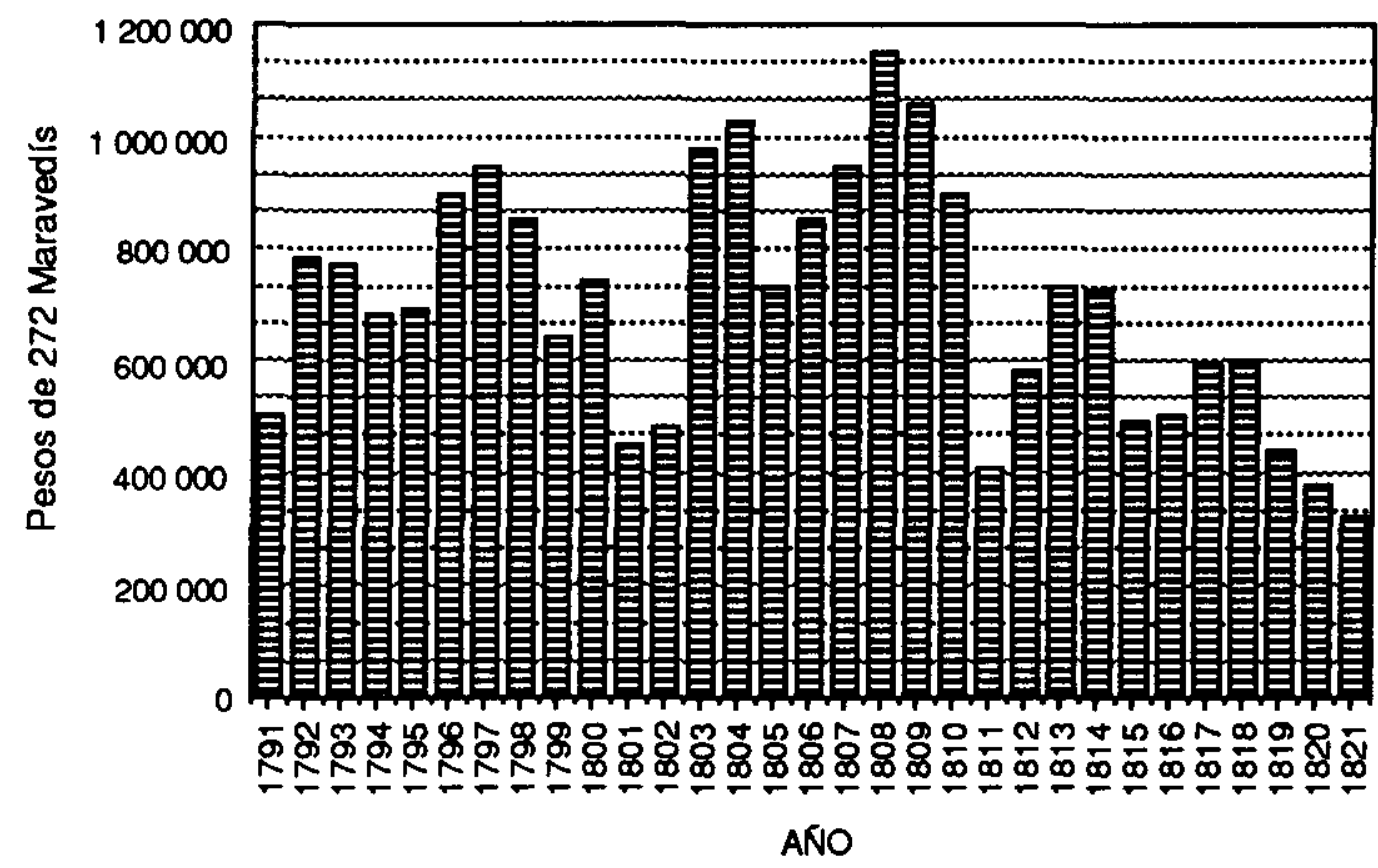

Fuente: Las cuentas de Zacatecas se encuentran en AGI, Guadalajara, legajos 481-82 y AGI, México, Legajos 2032, 2034, y 2376. La Biblioteca William Clements de Ann Arbor, Michigan, tiene las cuentas de 1807-12, 1814-15, 1817-19 y 1821 en su colección de Zacatecas.

\section{Gráfica 5}

DERECHOS SOBRE PLATA, REAL CAJA DE ZACATECAS, 1791-1821

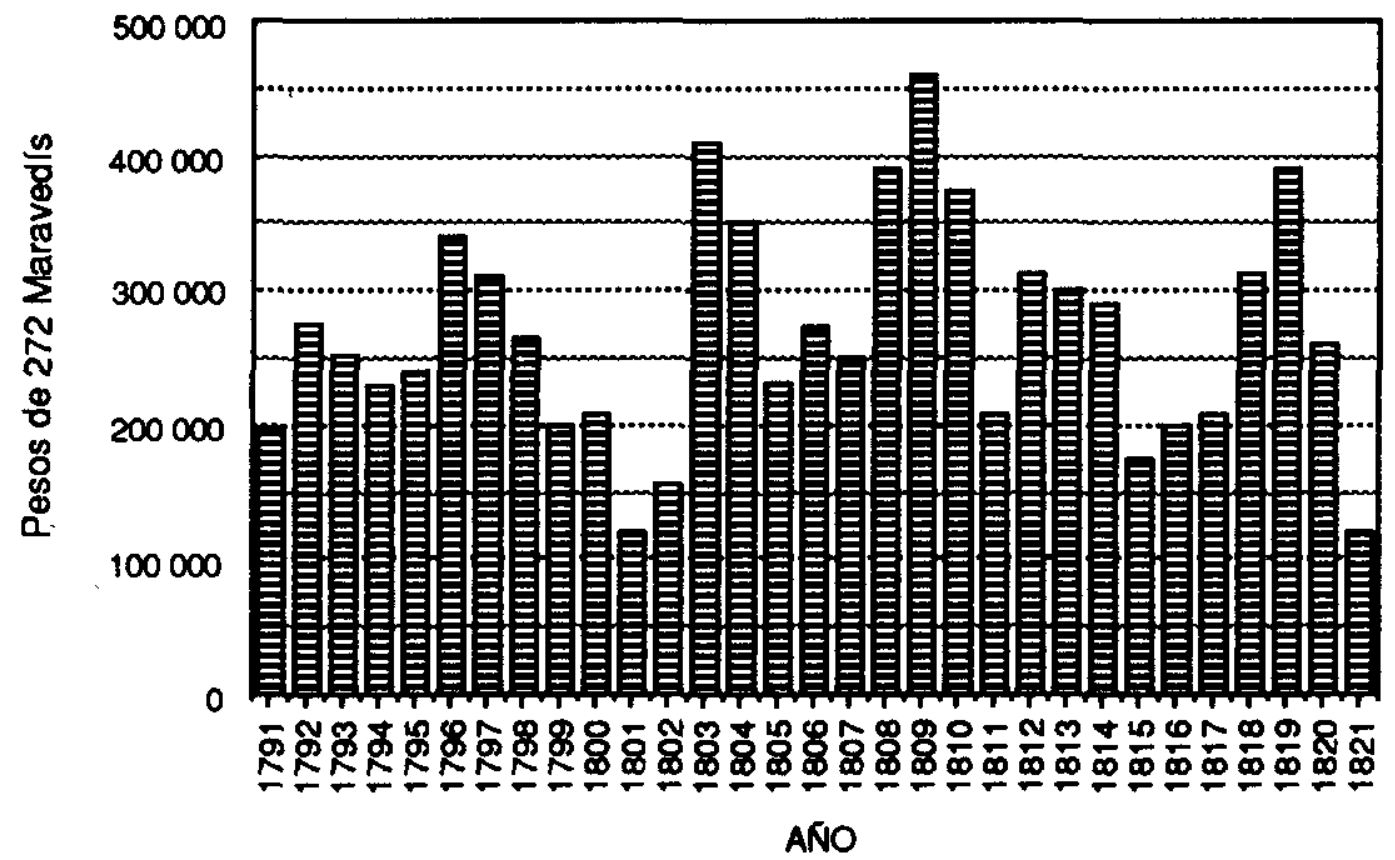

Fuente: Véase gráfica 4. 


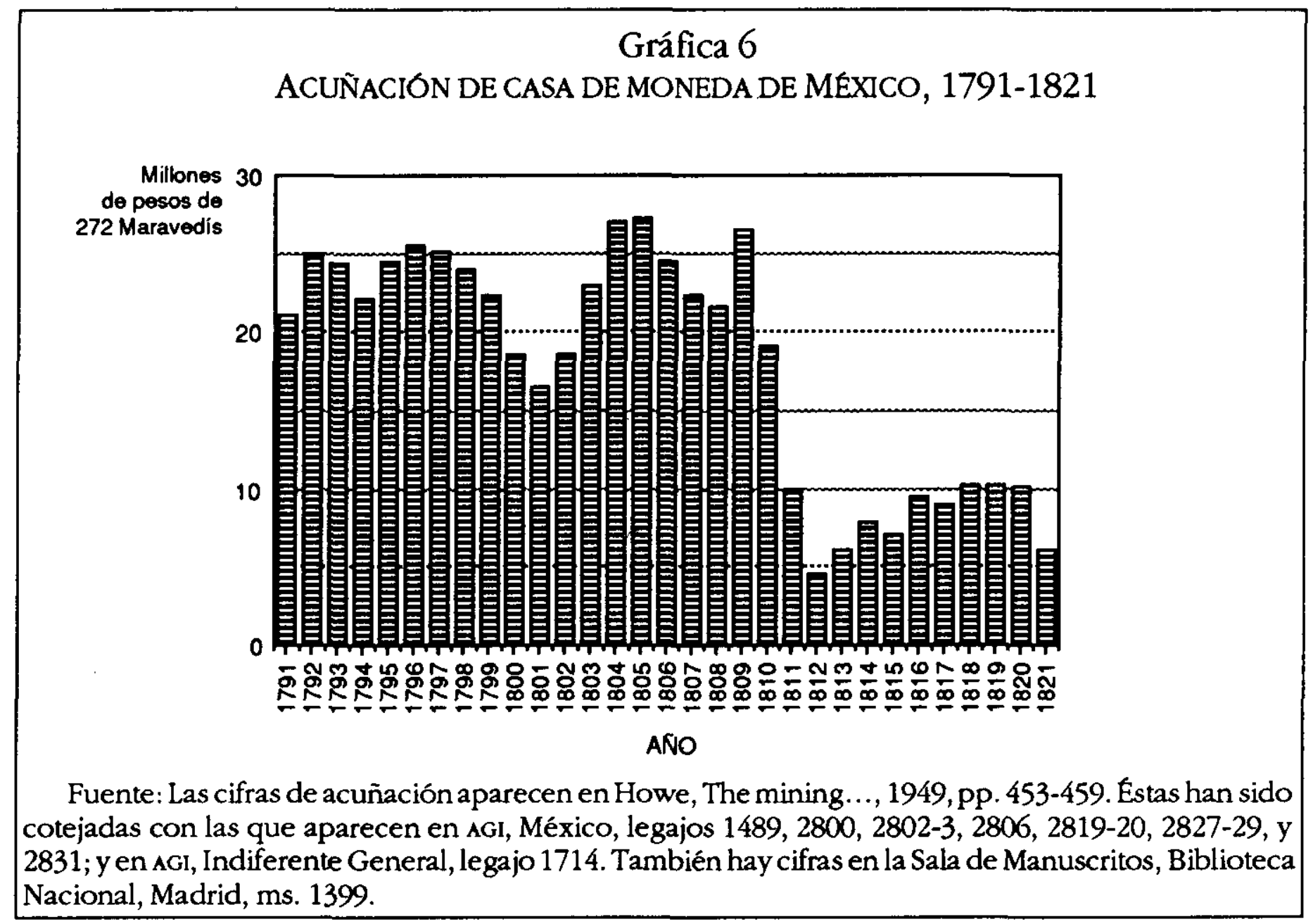

\section{Gráfica 7}

DÉBITOS DE LA REAL HACIENDA DE MÉXICO, 1791-1817

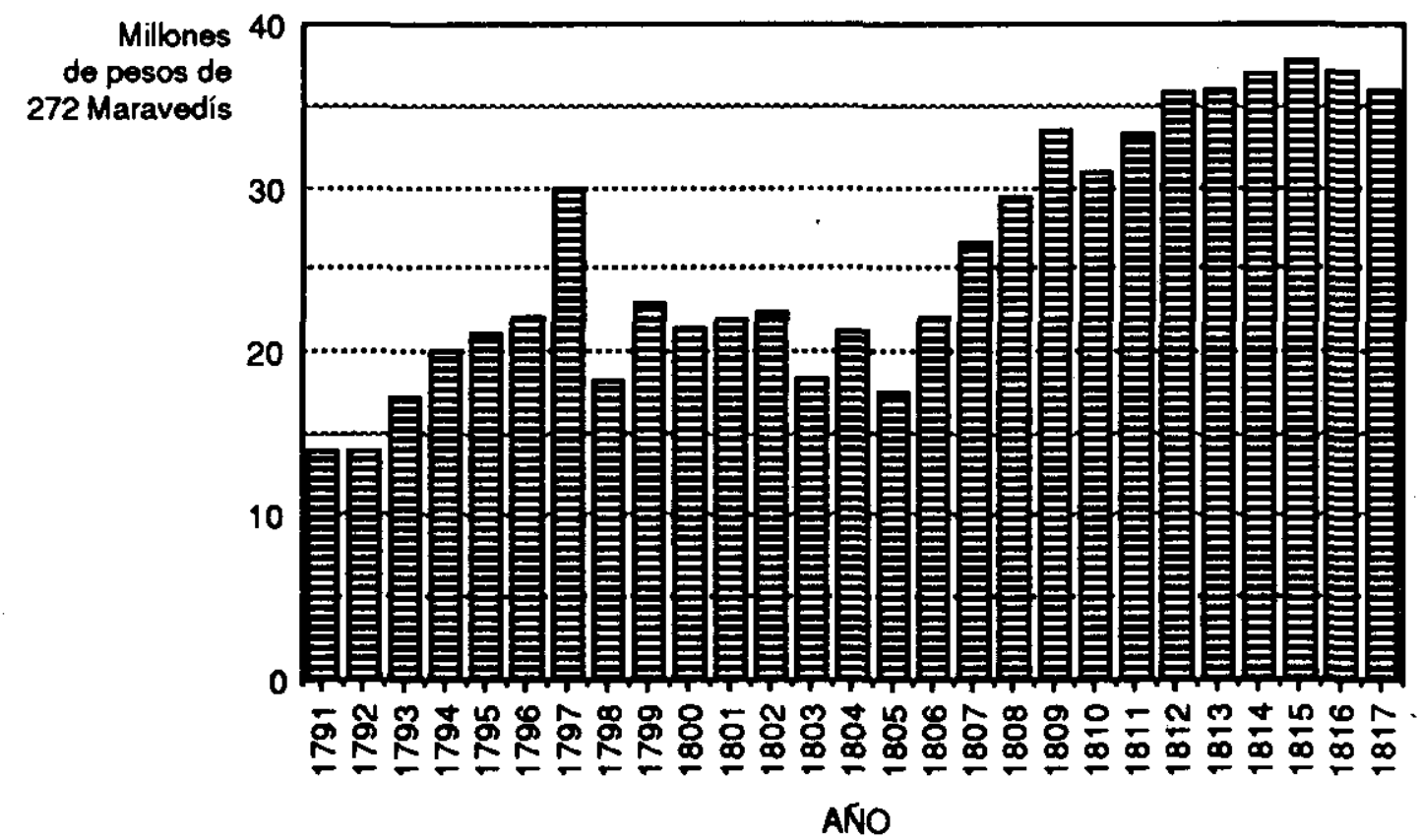

Fuente: Relaciones anuales de la deuda de la real hacienda en México se encuentran en AGI, México, legajos 2020, 2022-23, 2026, 2355-58, 2360, 2366, 2373, 2375, y 2387. 

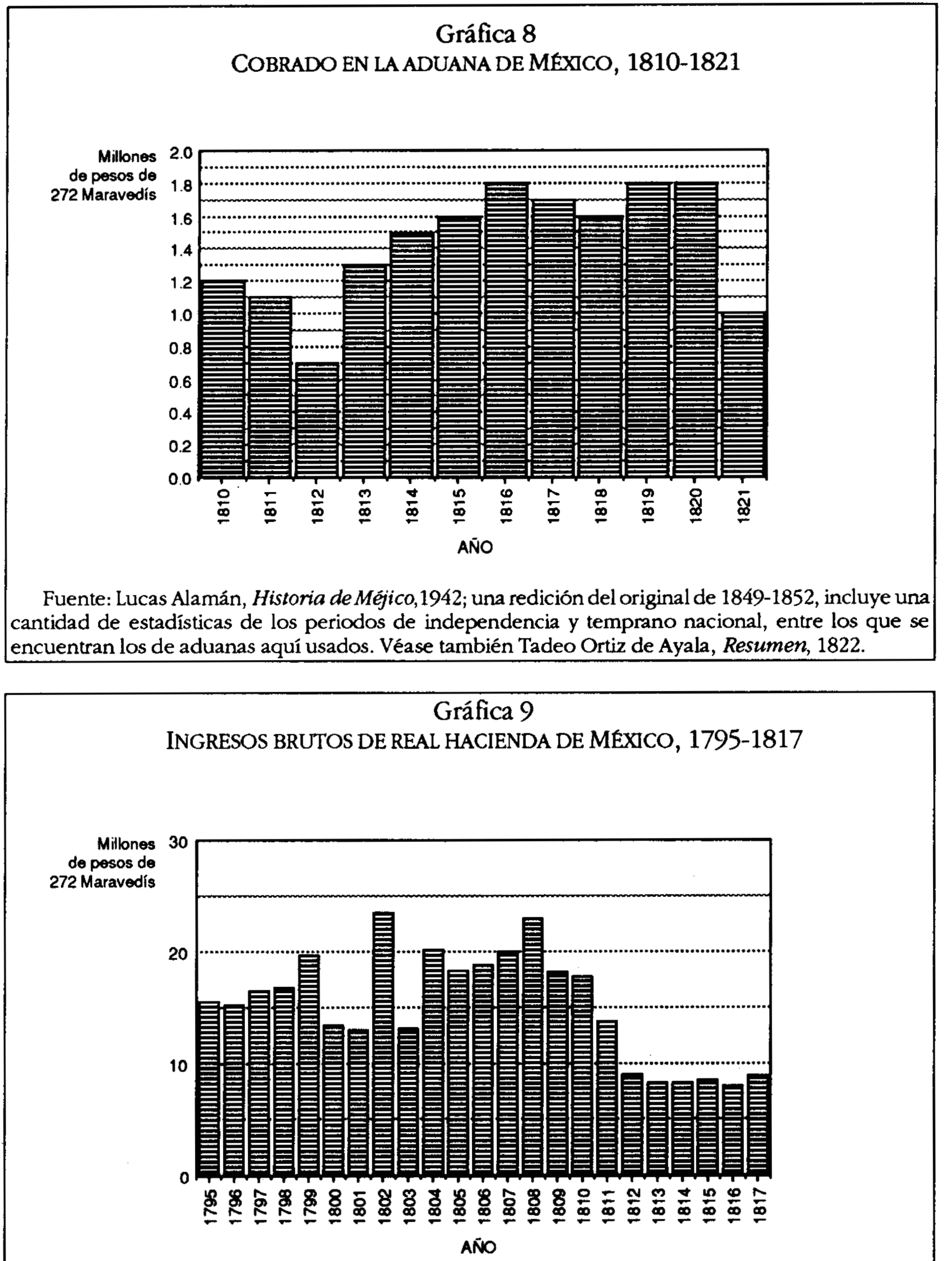


\section{Gráfica 10}

GASTOS DE GUERRA Y SITUADOS REAL HACIENDA DE MÉXICO, 1795-1817

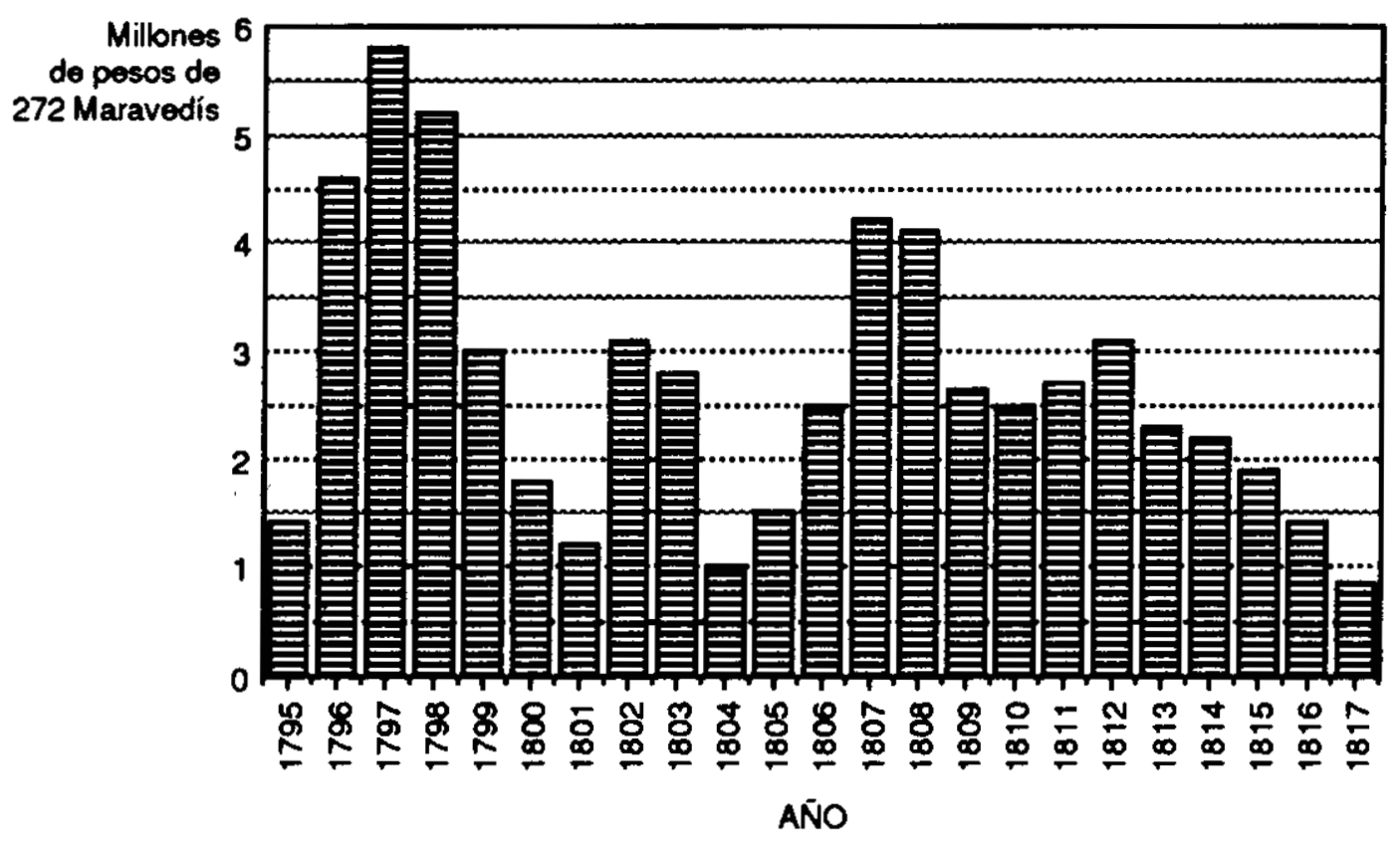

\section{Gráfica 11}

SITUADOS REMITIDOS A FILIPINAS Y GRAN CARIBE, 1795-1817

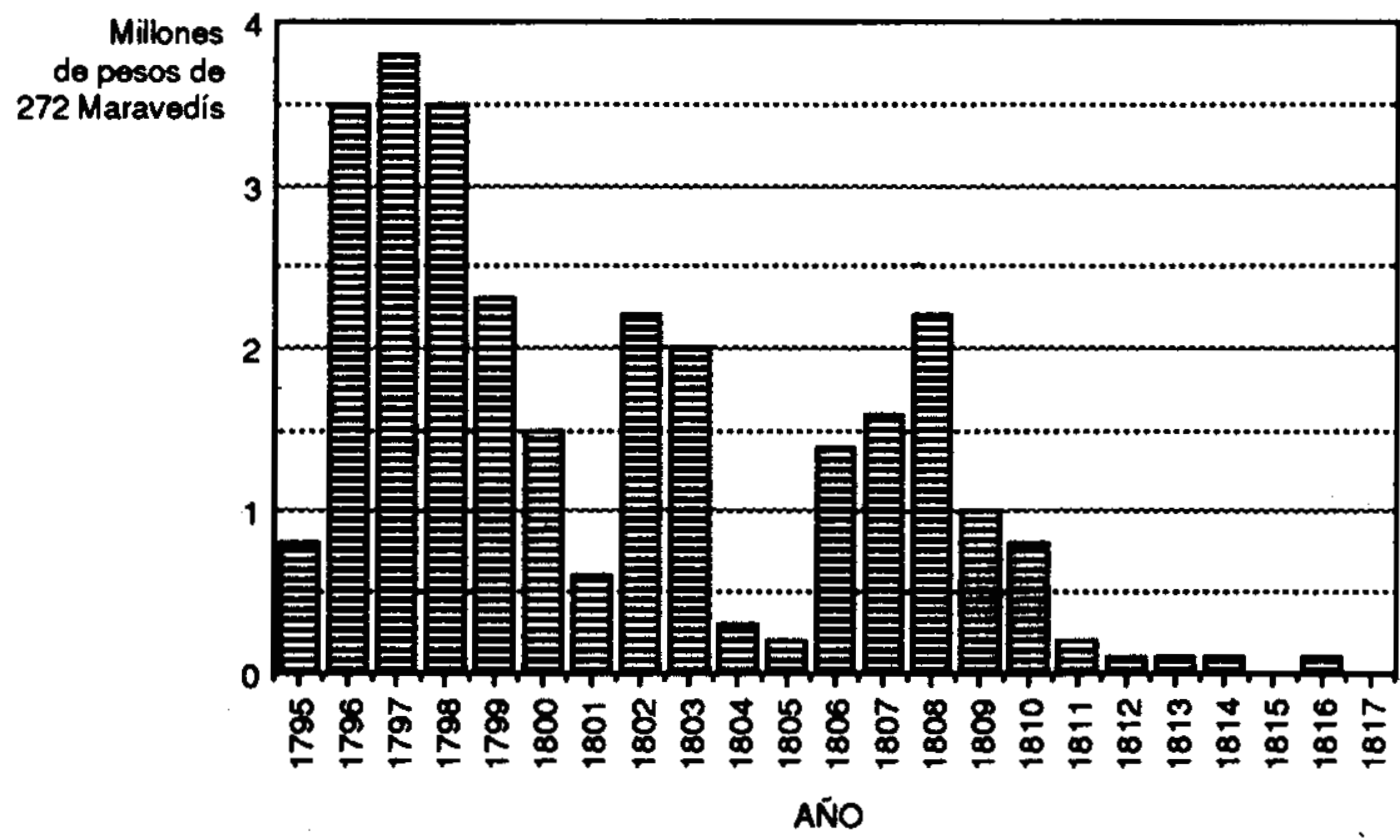

